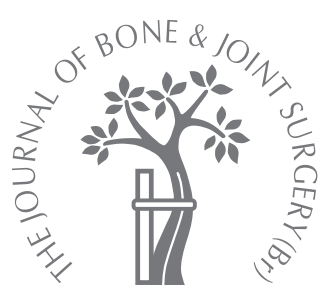

F. Chotel,

A. Unnithan,

C. R. Chandrasekar,

R. Parot,

L. Jeys,

R. J. Grimer

From The Royal

Orthopaedic

Hospital Oncology

Service, Birmingham,

England

In F. Chotel, MD, PhD,

Orthopaedic Surgeon

R. Parot, MD, Paediatric

Surgeon

Service Orthopédie, Hôpital

Universitaire Mère Enfant de

Lyon, 59 Boulevard Pinel, 69677

Bron cedex, France.

A. Unnithan, MRCS, MSc,

Specialist Registrar in

Orthopaedics

Frimley Park Hospital

Portsmouth Road, Frimley,

Surrey GU16 7UJ, UK.

E. R. Chandrasekar $\mathrm{MCh}$ (Orth), FRCS(Orth),

Orthopaedic Surgeon

- L. Jeys, FRCS, Orthopaedic

Surgeon

R. J. Grimer, FRCS,

Orthopaedic Surgeon

The Royal Orthopaedic

Hospital, Bristol Road South,

Northfield, Birmingham B31

2AP, UK.

Correspondence should be sent to Dr F. Chotel; e-mail:

franck.chotel@yahoo.co.uk

(c) 2008 British Editorial Society of Bone and Joint Surgery doi:10.1302/0301-620X.90B8. $19815 \$ 2.00$

$J$ Bone Joint Surg $[\mathrm{Br}]$ 2008;90-B:1090-6.

Received 13 June 2007;

Accepted after revision 5 March 2008

\title{
Variability in the presentation of synovial sarcoma in children
}

\author{
A PLEA FOR GREATER AWARENESS
}

We have analysed the pattern of symptoms in patients presenting with synovial sarcoma to identify factors which led to long delays in diagnosis. In $\mathbf{3 5}$ children, the early symptoms and the results of clinical and radiological investigation were reviewed, along with the presumed diagnoses. The duration of symptoms was separated into patient delay and doctor delay.

Only half of the patients had one or more of the four clinical findings suggestive of sarcoma according to the guidance of the National Institute for Clinical Excellence at the onset of symptoms. Of the 33 children for whom data were available, $16(48.5 \%)$ presented with a painless mass and in ten $(30.3 \%)$ no mass was identified. Seven $(21.2 \%)$ had an unexplained joint contracture. Many had been extensively investigated unsuccessfully. The mean duration of symptoms was 98 weeks ( 2 to 364), the mean patient delay was 43 weeks ( 0 to 156) and the mean doctor delay was 50 weeks ( 0 to 362). The mean number of doctors seen before referral was three ( 1 to 6 ) and for 15 patients the diagnosis was obtained after unplanned excision. Tumours around the knee and elbow were associated with a longer duration of symptoms and longer doctor delay compared with those at other sites. Delays did not improve significantly over the period of our study of 21 years, and we were unable to show that delay in diagnosis led to a worse prognosis.

Our findings highlight the variety of symptoms associated with synovial sarcoma and encourage greater awareness of this tumour as a potential diagnosis in childhood.

Synovial sarcoma accounts for approximately $1 \%$ of all childhood malignancy. ${ }^{1}$ Although rare, it is the most common non-rhabdomyosarcoma and represents approximately $30 \%$ of soft-tissue sarcomas seen in childhood. ${ }^{2,3}$ The size of the tumour at presentation is the most important predictor of survival for patients with synovial sarcoma. ${ }^{4-6}$ Studies in patients of all ages have correlated younger age with a better prognosis, but since the size of the tumour also varies with age, there is no convincing evidence that age is an independent prognostic factor. $^{7}$

The early diagnosis of any soft-tissue sarcoma should lead to a better outcome, since it will be smaller and it should prove easier to obtain clear excisional margins. ${ }^{8,9}$ Synovial sarcomas, however, are unusual because they often do not present in a manner typical of soft-tissue sarcoma and delays in diagnosis are frequent. ${ }^{10,11}$ Furthermore, it is not uncommon for patients to have excision of a lump, without the suspicion that it could be a sarcoma, which results almost inevitably in contaminated margins and the need for further surgery.
Our aim was to identify the early symptoms, physical findings, the radiological presentation of synovial sarcoma in children and the factors which led to delay and inappropriate resection of such tumours.

\section{Patients and Methods}

Between 1985 and 2006, 35 consecutive patients with a newly-diagnosed, histologicallyconfirmed synovial sarcoma were registered on our database. Details such as the age at diagnosis, gender, side, site, size and volume at the time of surgery, the duration of symptoms and the type of procedure performed to obtain the histological diagnosis were noted. The histological findings were all reviewed. There were 22 boys and 13 girls aged between 3 and 16 years (mean 12.3 years) (Fig. 1 ).

The records of each patient were analysed retrospectively to determine the clinical presentation at the first medical visit and subsequent radiological features. In the clinical presentation we looked for a history of trauma, the nature of any pain, the presence or absence of swelling, tenderness, an enlarging 


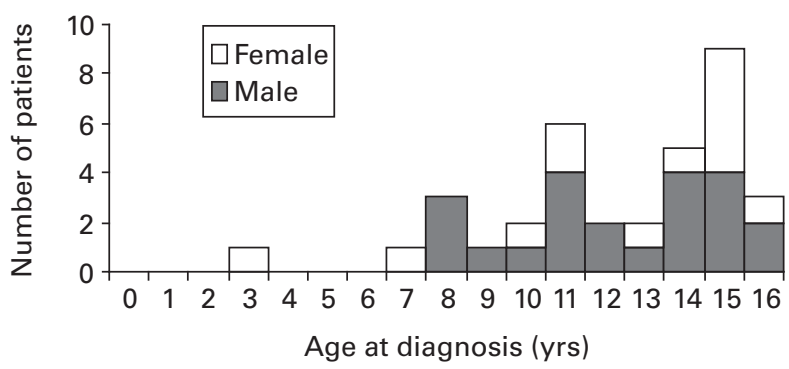

Fig. 1

Bar chart showing the distribution of the 35 children according to age at diagnosis and gender.

mass, limping, chronic joint contracture and neurological symptoms. We noted the initial clinically presumed diagnosis. Calcification on plain radiographs and the presumed diagnosis of the radiologist after MRI were also recorded.

Guidance produced by the National Institute for Clinical Excellence (NICE) $)^{10,12}$ suggests that there are four clinical features suggestive of malignancy in a soft-tissue swelling, namely size $>5 \mathrm{~cm}$, location beneath the deep fascia, an increase in size and an increase in pain. In children, the guidance is even more specific, recommending that any lump $>2 \mathrm{~cm}$ in size should be referred for investigation. ${ }^{10}$ The presence of these features was analysed both at the first medical visit and at the time of diagnosis.

In order to assess the likely cause of a delay in diagnosis, we used the criteria of Widhe and Widhe, ${ }^{13}$ who defined 'patient delay' as that from the time at which symptoms were first noted until the time when the patient first consulted a doctor, and 'doctor delay' from the first medical visit until an accurate diagnosis was established. The number of doctors who were consulted before the patient was referred to the specialist centre, and their specialty was also noted.

Statistical analysis. For comparison of mean values, tests appropriate to the group size (non-parametric on the Mann-Whitney U test) were used. For qualitative variable comparisons, Fisher's exact test was used. The logiciel BMDP dynamic 7.0 program (BMDP Statistical Software Inc., Los Angeles, California) was used for statistical analysis. The significance level was set at $\mathrm{p} \leq 0.05$. Survival estimates were calculated using the Kaplan-Meier survival analysis.

\section{Results}

The tumours were mainly in the limbs with only four cases of truncal sarcoma. The most frequent locations were the thigh and knee in 20 patients $(57 \%$, Table I). Of the tumours, 28 were beneath the deep fascia $(80 \%)$ and seven were superficial $(20 \%)$. There were 13 adjacent to a joint capsule and hence peri-articular. No patient had a true intra-articular lesion.
Table I. Details of the location of the primary tumour and the mean duration of symptoms

\begin{tabular}{llc}
\hline Primary site & Number of cases (\%) & $\begin{array}{c}\text { Mean duration of } \\
\text { symptoms (wks) }\end{array}$ \\
\hline $\begin{array}{l}\text { Lower limb } \\
\text { Thigh }\end{array}$ & $26(75)$ & 51 (2 to 144) \\
Knee & 11 & 148 (13 to 364) \\
Shin & 9 & 71 (26 to 156) \\
Foot & 4 & 260 (208 to 312) \\
Trunk & 2 & \\
Neck & $4(11)$ & 18 (12 to 24) \\
Chest wall & 2 & 9 \\
Buttock & 1 & 34 \\
Upper limb & 1 & \\
Elbow & & 202 (40 to 364) \\
Forearm & $5(14)$ & 86 (16 to 156) \\
Hand (palmar) & 2 & 30 \\
Complete series & 2 & 98 (2 to 364) \\
\hline
\end{tabular}

The mean duration of symptoms was 98 weeks ( 2 to 364 , $\mathrm{n}=34$ ). Data were incomplete in five patients which prevented determination of patient and doctor delays in those cases (Fig. 2). The mean patient delay before a doctor was first seen was 43 weeks ( 0 to 156 ) and the mean doctor delay until a correct diagnosis was made was 50 weeks ( 0 to 362). There were 14 children who had symptoms for more than one year and nine for three or more years before diagnosis.

Tumours around the knee and elbow had a longer duration of symptoms (Mann-Whitney test, $\mathrm{p}=0.05$ ) and doctor delay (Mann-Whitney test, $\mathrm{p}=0.04$ ) compared with those elsewhere, but the patient delay showed no difference (Mann-Whitney test, $\mathrm{p}=0.14$ ). There was no correlation between patient and doctor delays (Mann-Whitney test, $\mathrm{p}=0.57)$. The initial symptoms $(\mathrm{n}=33)$ and physical findings both at presentation and at diagnosis are given in Table II $(\mathrm{n}=31)$. In ten patients pain preceded the recognition of a lump, but by the time of diagnosis 26 of 31 patients $(84 \%)$ had a palpable lump which was painful in $15(57 \%)$. In seven, the initial complaints were of a chronic joint contracture, six of which were painful. One patient presented with a joint contracture as the only symptom (Fig. 3). In one case the initial symptoms were of a pulmonary metastasis without any local features in the hand which was eventually found to be the primary site.

The mean size of the tumour at diagnosis was $6 \mathrm{~cm}$ (1 to $18, \mathrm{n}=30) ; 13$ were $<5 \mathrm{~cm}, 11$ between 5 and $10 \mathrm{~cm}$, and six were $>10 \mathrm{~cm}$. The mean volume at diagnosis was $110 \mathrm{~cm}^{3}$ (1 to 973). No correlation was found between the presence of pain and the size or depth of the tumour or between the size and the duration of symptoms. The factors associated with the mean patient and doctor delays are given in Table III. With regard to initial symptoms, the pres- 


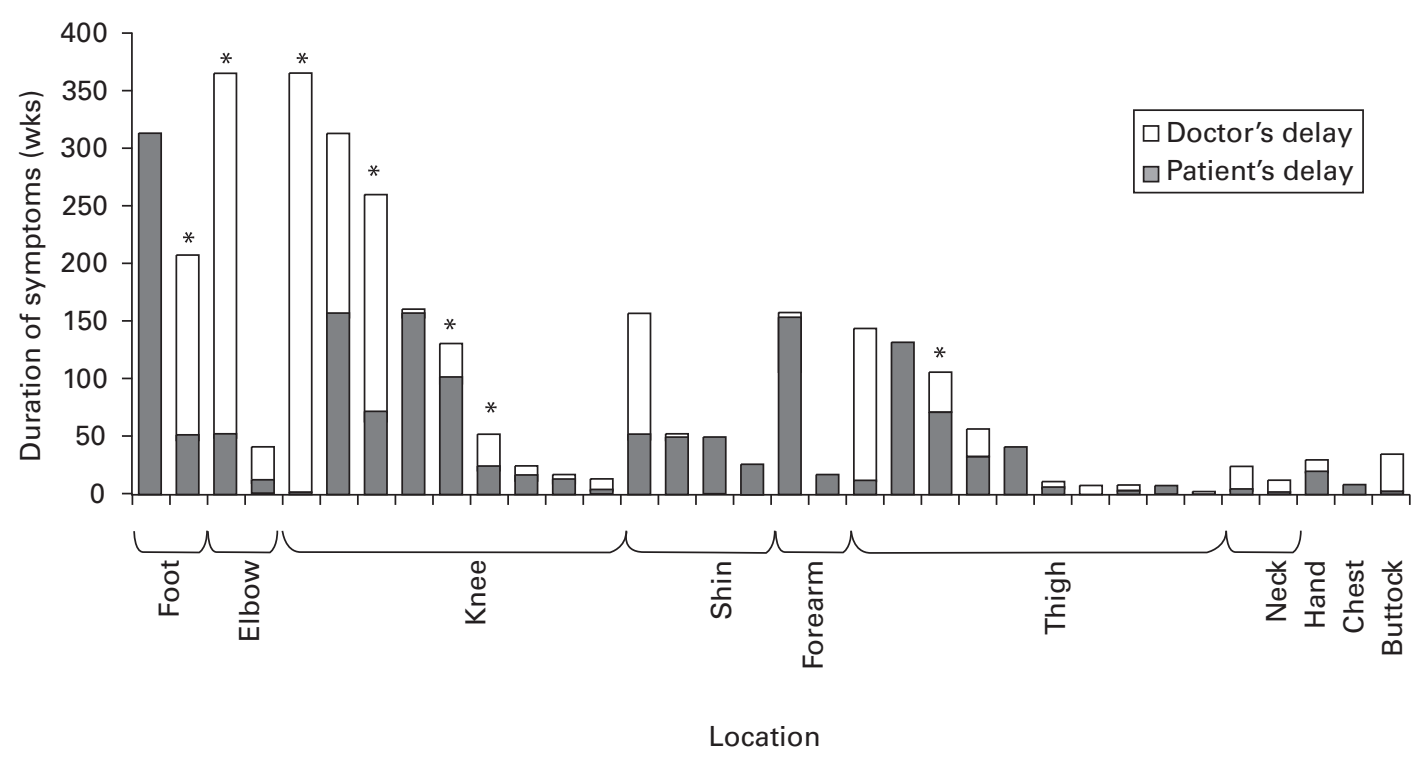

Fig. 2

Bar chart showing the duration of symptoms in weeks according to the location of the synovial sarcoma. For five patients, the patient and doctor delays were not available $(*$, symptoms of chronic joint contracture).

Table II. Details of the locoregional initial symptoms and findings at diagnosis

\begin{tabular}{|c|c|c|}
\hline Symptoms & Initial symptoms $(\mathrm{n}=33)^{*}$ & Physical findings at diagnosis $(n=31)$ \\
\hline \multicolumn{3}{|l|}{ Lump } \\
\hline Painless & 16 & 11 \\
\hline Painful & 6 & 15 \\
\hline Pain without lump & 10 & 3 \\
\hline Tenderness & 7 & 14 \\
\hline Swelling & 13 & 20 \\
\hline Increase in size & - & 17 \\
\hline Fixed joint contracture & 7 & 7 \\
\hline Limp & 1 & 2 \\
\hline Giving way & 1 & 0 \\
\hline Paraesthesia & 0 & 1 \\
\hline
\end{tabular}

ence of a peri-articular lump (Mann-Whitney test, $\mathrm{p}=0.015$ ) or a joint contracture (Mann-Whitney test, $\mathrm{p}=0.0008$ ) or the absence of a lump (Mann-Whitney test, $\mathrm{p}=0.0003$ ) contributed to doctor delay, while the main cause of patient delay was the presence of a peri-articular lump (Mann-Whitney test, $\mathrm{p}=0.02$ ).

At the time of the initial symptoms, only half of the patients had one or more of the four clinical findings suggestive of sarcoma according to the NICE guidelines. ${ }^{10,12}$ Ten children did not have a lump and in six others, the mass was painless, small $(<5 \mathrm{~cm})$ and superficial. There were insufficient data in this retrospective study to identify if the size at original presentation to a doctor was more or less than $2 \mathrm{~cm}$.
By the time of the eventual diagnosis, all the patients, except one, had one or more of the four clinical features suggestive of malignancy. The only patient with negative criteria had a superficial, painless lump in the leg, $3 \mathrm{~cm}$ in size, which had not increased.

The presumed initial diagnosis after the first clinical assessment by the general practitioner (GP) or orthopaedic surgeon and the radiological diagnosis after MRI are shown in Table IV. The patients had consulted a mean of three doctors (1 to 6) before referral to the oncology centre. Doctors involved in diagnosis were mainly GPs (25 patients) and orthopaedic surgeons (31 patients). Because of joint contracture, five rheumatological referrals were made. 


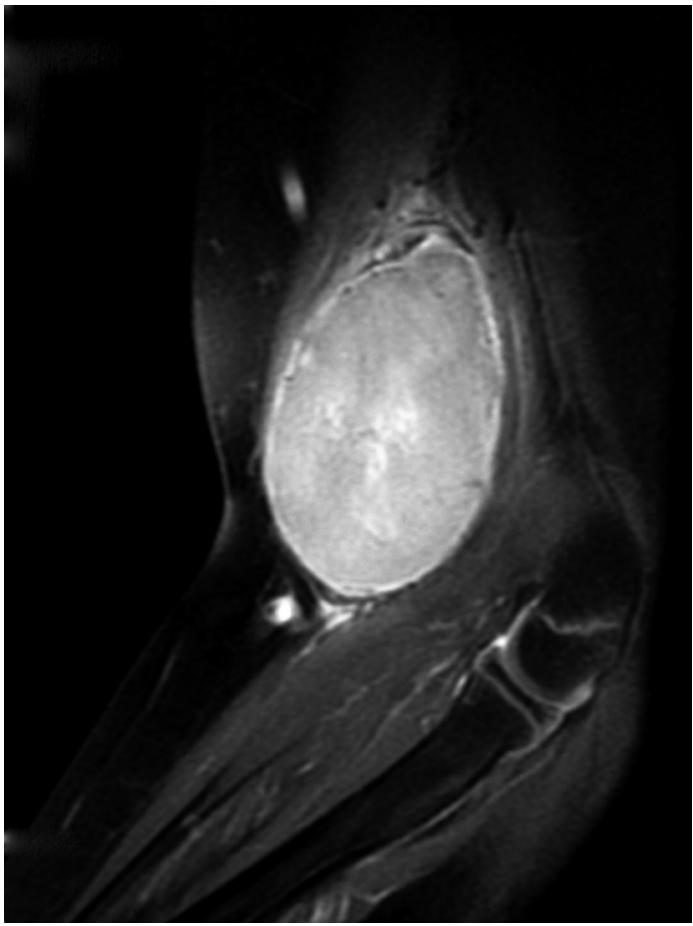

Fig. $3 a$

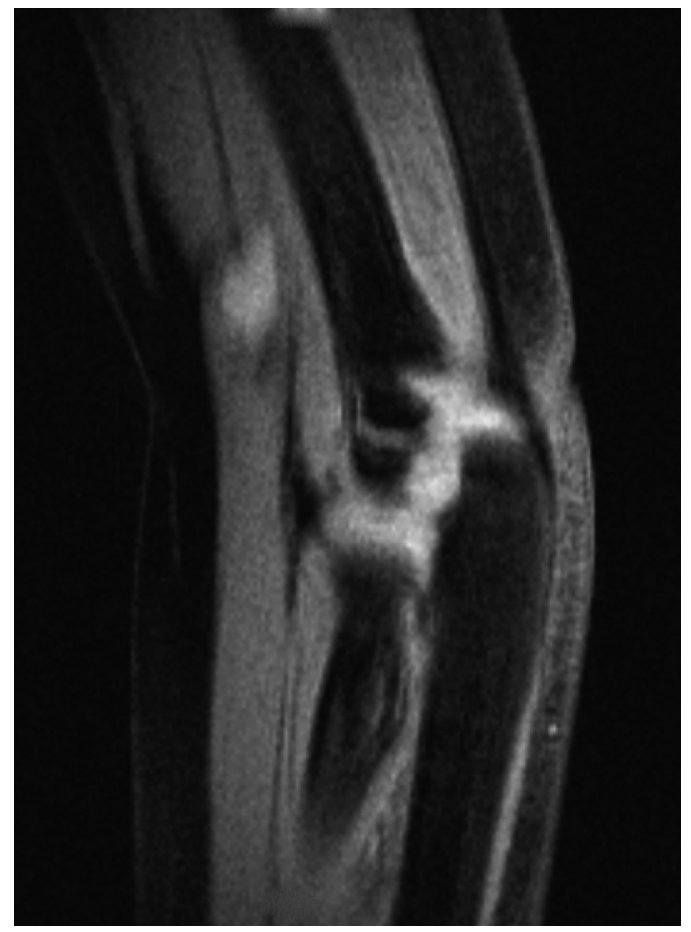

Fig. $3 b$

MRI of a) an 11-year-old girl who was referred with a soft-tissue mass in the elbow. The longstanding history began with a progressive flexion contracture when she was four years of age, and b) at five years of age retrospectively showing an abnormal signal that had been interpreted as normal. In the absence of a lump and of pain, the diagnosis of a tight brachialis tendon and later of focal myositis was considered. After years of unsuccessful management by five different doctors, the correct diagnosis was established.

Two patients had non-diagnostic aspiration of the swelling, in one for a presumed Baker's cyst and in the other for a suspected haematoma.

In our unit, the diagnosis of synovial sarcoma was obtained after either needle biopsy in six patients, open biopsy in nine, or excisional biopsy for small lesions in three. There were 15 patients referred with a histology report of synovial sarcoma after an unplanned excision; all underwent a wide re-excision. One child with a tumour outside the capsule of the knee was diagnosed after an arthroscopic biopsy. Because of joint contamination, an extra-articular resection of the knee and prosthetic replacement were carried out.

The mean size of tumours diagnosed after unplanned excision $(3.6 \mathrm{~cm} ; 1$ to 11$)$ was smaller than the mean size of tumours diagnosed by other methods $(8.1 \mathrm{~cm} ; 1$ to 18$)$ (Mann-Whitney test, $\mathrm{p}=0.003$ ). Two patients had longstanding symptoms and the doctor delay was because of incorrect histological interpretation. Both patients had a monophasic synovial sarcoma enveloping a nerve. The first was a 14-year-old boy with a mass of $13 \mathrm{~cm}$ in the anterior compartment of his thigh which had been diagnosed initially as a Schwannoma and removed with an equivocal margin. Because of local recurrence the tumour was re-excised and a review of the original histology led to the correct diagnosis (doctor delay 132 weeks). The second was a 12 -year-old boy with a soft-tissue mass in the hamstrings $6 \mathrm{~cm}$ in size. He had an excisional biopsy and an initial diagnosis of a neurilemmoma. Six months later, after histological review, the diagnosis was corrected.

The mean doctor delay for tumours managed before 1996 (72 weeks (SD 81)) was no better than that after this time (56 weeks (SD 100); Mann-Whitney test, $\mathrm{p}=0.29$ ).

In all cases, surgical excision attempted to achieve wide margins. In addition, 19 patients received chemotherapy, 13 as neoadjuvant treatment. Of the latter, none had a complete response but five showed slight shrinkage of the tumour. None had necrosis of more than $50 \%$ on histological evaluation. The overall survival was $88 \%$ at five years. There were four deaths which did not allow any significant prognostic factor to be identified. The mean duration of symptoms for those who died was 45 weeks compared with 105 for the survivors, but this was not significant. Nor was there a significant difference in the size of the tumour at diagnosis.

\section{Discussion}

Although many studies have concentrated on the treatment and prognosis of synovial sarcoma, ${ }^{7,14-16}$ few have 
Table III. The mean (SD) patient and doctor delay according to the different clinical features

\begin{tabular}{|c|c|c|c|c|}
\hline Variable & Mean patient delay & p-value & Mean doctor delay & p-value \\
\hline Initial painless mass & & 0.12 & & $0.0105^{*}$ \\
\hline No $(n=16)$ & $42.43(42.30)$ & & $96.37(114.11)$ & \\
\hline Yes $(n=12)$ & $35.08(57.61)$ & & $8.08(8.2)$ & \\
\hline Lump as first symptom & & 0.1 & & $0.0003^{*}$ \\
\hline No $(n=11)$ & $51.54(47.35)$ & & $128.09(123.3)$ & \\
\hline Yes $(n=17)$ & $31.35(49.10)$ & & $13.53(24.77)$ & \\
\hline Size & & 0.19 & & 0.104 \\
\hline$<5 \mathrm{~cm}(\mathrm{n}=11)$ & $39.72(44.54)$ & & 82.45 (113.58) & \\
\hline$>5 \mathrm{~cm}(\mathrm{n}=13)$ & $31.61(47.27)$ & & $39.54(89.21)$ & \\
\hline Increase in size & & 0.48 & & 0.11 \\
\hline No $(n=13)$ & $46.17(55.21)$ & & $90.83(111.08)$ & \\
\hline Yes $(n=13)$ & $36.13(44.9)$ & & $36(80.72)$ & \\
\hline Deep & & 0.41 & & 0.72 \\
\hline No $(n=5)$ & $18.4(20.5)$ & & 26.6 (43.38) & \\
\hline Yes $(n=23)$ & $43.8(51.9)$ & & $65.48(103.53)$ & \\
\hline Peri-articular location & & $0.02^{*}$ & & $0.015^{*}$ \\
\hline No $(n=15)$ & $22.2(39)$ & & $22.06(39.90)$ & \\
\hline Yes $(n=13)$ & $59 \quad(52.4)$ & & $100.61(123.92)$ & \\
\hline Fixed joint contracture & & 0.08 & & $0.0008^{*}$ \\
\hline No $(n=21)$ & $34.48(52.54)$ & & $25.38(45.44)$ & \\
\hline Yes $(n=7)$ & $53.71(33.07)$ & & $158 \quad(139)$ & \\
\hline Calcifications on radiographs & & 0.42 & & 0.15 \\
\hline No $(n=18)$ & $37.44(50.16)$ & & $47.22(81.46)$ & \\
\hline Yes $(n=6)$ & $59.67(56.36)$ & & $124.17(140.9)$ & \\
\hline Biopsy procedure & & $0.03^{*}$ & & 0.08 \\
\hline Unplanned excision $(n=13)$ & $62.9(60)$ & & $82.8(108)$ & \\
\hline Other $(n=15)$ & $18.8(22)$ & & $37.5(83)$ & \\
\hline
\end{tabular}

described the initial presentation and management before referral to a specialist centre.

Some synovial sarcomas grow quickly but most progress slowly and may be latent for several years. The mean duration of symptoms before diagnosis in our study was 98 weeks ( 2 to 364 ). Israels et al ${ }^{17}$ recorded a mean duration of symptoms of two years before diagnosis in seven children. Unlike bone tumours, which usually have specific radiological signs of malignancy, there are no such reliable prebiopsy tests for soft-tissue sarcomas. ${ }^{18}$ The mean duration of symptoms in children with synovial sarcoma is very long compared with that for osteosarcoma and Ewing's sarcoma, 13 to 15 and 34 to 37 weeks, respectively. ${ }^{13,19}$ The delay in diagnosis in our series was similar to that of other studies. ${ }^{11}$ The most dangerous misconception regarding a soft-tissue mass is that there is no need for concern unless it is painful. ${ }^{18}$

Our study has shown that the presenting mass was often painless, similar to a benign lesion. An increase in size may cause local discomfort because of pressure on surrounding structures. Four of the 16 children with an initially painless lump developed pain because of increasing size and deep location, but 11 still had a painless mass when diagnosed. Six had a superficial, painless mass, unchanging in size. These patients did not fit the guidelines for early referral of soft-tissue sarcoma and five were only diagnosed because an excisional biopsy was undertaken.

A mass which was painful at an early stage was seen in only six patients, and was more common by the time of diagnosis (15 patients, Table II). As further evidence of the atypical presentation of synovial sarcoma in children, in ten patients the presence of pain preceded the discovery of a soft-tissue mass. All of these were found eventually to have a deeply located tumour which could explain the difficulty in palpating it. Our findings were in agreement with other authors ${ }^{9,20}$ who reported that synovial sarcoma may be an explanation for persistent pain in children.

Six of the ten patients with pain but no lump presented with a painful chronic joint contracture which may have been due to contact between the tumour and the joint cap- 
Table IV. Details of the initial presumed diagnosis after the first clinical assessment by a GP or orthopaedic surgeon and after MRI (five patients did not have MRI before excisional biopsy)

\begin{tabular}{lll}
\hline Initial presumed diagnosis & After first clinical assessment (n = 35) & After MRI (n= 30) \\
\hline Soft-tissue sarcoma & 6 & 15 \\
Ganglion cyst & 3 & 2 \\
Baker's cyst & 2 & 1 \\
Lipoma & 2 & 1 \\
Schwannoma or neurilemmoma & 2 & 1 \\
Haematoma & 4 & - \\
Myositis ossificans & 3 & - \\
Infected lymph node & 2 & - \\
Fibromatosis & 2 & - \\
Reflex sympathetic dystrophy & 1 & 1 \\
Pigmented villonodular synovitis & - & 1 \\
Bursitis & 1 & - \\
Juvenile rheumatoid arthritis & 1 & - \\
Epidermoid cyst & 1 & - \\
Benign inflammatory mass & - & 1 \\
No orientation given or no data available & 5 & 7 \\
\hline
\end{tabular}

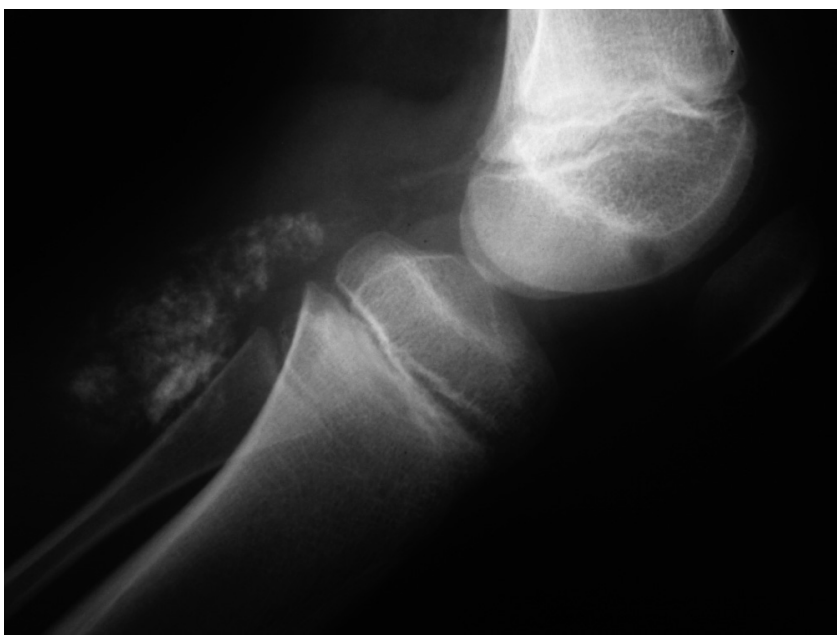

Fig. 4

Radiograph of a painless calcified soft-tissue popliteal mass. After regular follow-up for seven years while the lesion slowly increased in size, excision resulted in the diagnosis of synovial sarcoma. A wide reexcision was needed to achieve clear margins.

sule or an adjacent nerve. There were seven chronic contractures in 13 peri-articular tumours. The joints involved included four knees, with two tumours in the lateral knee capsule, one medial and one in the popliteal fossa, one in the sinus tarsi, one hip and one elbow. The mean duration of symptoms before diagnosis in patients with a joint contracture as the presenting feature was four years and none was diagnosed less than one year after the onset of symptoms.

It has been suggested that plain radiography and MRI should be undertaken in every child with an unexplained chronic contracture. ${ }^{21}$ Two patients were investigated for chronic contracture and had MRI at an early stage. Their scans were reported as having no tumour identified and this conclusion led to the longest doctor delays in our series, 312 and 362 weeks (Fig. 3).

The main radiological fallacy was to consider that the presence of calcification or ossification was not a cause for concern. A central or disorganised pattern of dystrophic mineralisation within a soft-tissue tumour should suggest the diagnosis of synovial sarcoma ${ }^{18}$ (Fig. 4) since calcification is seen in approximately $25 \%$ of such tumours. ${ }^{22}$ Neurofibrosarcoma and fibrosarcoma may also have intralesional calcification, but these tumours occur very rarely in children and synovial sarcoma is the most common tumour with this finding. ${ }^{23}$ Unfortunately, these features are not well known. In three patients myositis ossificans was considered even though this condition typically has other features, such as a peripheral rim of radiodensity. In any child with a calcified mass we recommend biopsy to ensure that a potential tumour has not been overlooked.

The most sensitive and specific method of imaging softtissue masses is $\mathrm{MRI}^{24}$ and although synovial sarcoma usually shows inhomogeneous tissue, it is uncommon to be able to make a specific diagnosis by MRI. In our study five patients did not have MRI before excisional biopsy. They had a clinical diagnosis of a ganglion or Baker's cyst, and in three this diagnosis was still suggested after MRI (Table IV). ${ }^{25}$

Delays in diagnosis cause great concern for patients. It is difficult to evaluate the effect on treatment or outcome. In general, faster-growing and more aggressive tumours present earlier and the long delays in diagnosis which we report suggest a relatively slow-growing tumour, which has been confirmed by the high survival rate of $88 \%$ at five years. ${ }^{11}$

The definitive diagnosis was obtained after an unplanned excision in nearly half of the patients. In these cases a patient delay was significantly higher than that of tumours 
diagnosed after other methods of diagnosis. A longstanding history before the first visit to a doctor suggested that the condition was benign and led to inadequate excision.

Histological diagnosis is sometimes difficult and in two patients led to a diagnosis of a tumour of a nerve sheath. In recent years, real time polymerase chain reaction studies have been helpful because of the finding of a characteristic translocation (X:18).

We plead for a greater awareness of synovial sarcoma as a potential diagnosis in childhood. This may lead to a reduction of doctor delay and earlier diagnosis. However, reduction of patient delay is much more difficult to achieve, and will only occur with increased public awareness of symptoms suggestive of malignancy. General practitioners, orthopaedic surgeons, rheumatologists and radiologists are the first clinicians encountered in the management of this tumour in children. In the United States the annual incidence of benign soft-tissue tumours is 300 per 100000 population compared with two per 100000 for malignant soft-tissue tumours; hence doctors more often encounter benign lesions, ${ }^{18}$ such as a popliteal cyst. ${ }^{26}$

An atypical clinical presentation necessitates examination by MRI. In the absence of typical MRI signs of a cyst, biopsy should be considered or the patient referred to a specialist centre. Synovial sarcoma remains a difficult tumour to diagnose accurately and it is better to overinvestigate benign lesions in order to reduce the incidence of missed or delayed diagnoses.

We wish to thank Ms Rabilloud and the Department of Biostatistics of the Hospices Civils de Lyon, Lacassagne F-69424, France.

No benefits in any form have been received or will be received from a commercial party related directly or indirectly to the subject of this article.

\section{References}

1. Grovas A, Fremgen A, Rauck A, et al. The National Cancer Data Base report on patterns of childhood cancers in the United States. Cancer 1997;80:2321-32.

2. Spunt SL, Poquette CA, Hurt YS, et al. Prognostic factors for children and adolescents with surgically resected nonrhabdomyosarcoma soft tissue sarcoma: an analysis of 121 patients treated at St Jude Children's Research Hospital. J Clin Oncol 1999; 17:3697-705.

3. McGrory JE, Pritchard DJ, Arndt CA, et al. Non rhabdomyosarcoma soft tissue sarcomas in children: the Mayo Clinic experience. Clin Orthop 2000;374:247-58.
4. Thompson RC Jr, Garg A, Goswitz J, et al. Synovial sarcoma: large size predicts poor outcome. Clin Orthop 2000;373:18-24.

5. Deshmukh R, Mankin HJ, Singer S. Synovial sarcoma: the importance of size and location for survival. Clin Orthop 2004;419:155-61.

6. Grimer RJ. Size matters for sarcomas! Ann R Coll Surg Eng/2006;88:519-24.

7. Ferrari A, Gronchi A, Casanova M, et al. Synovial sarcoma: a retrospective analysis of 271 patients of all ages at a single institution. Cancer 2004;101:627-34.

8. Henderson SA, Davis R, Nixon JR. Synovial sarcoma: a clinicopathological review. Int Orthop 1991;15:251-5.

9. McKee MD, Liu DF, Brooks JJ, et al. The prognostic significance of margin width for extremity and trunk sarcoma. J Surg Oncol 2004;85:68-76.

10. No authors listed. NICE Referral guidelines for suspected cancer 2005:27:43. http:/ /www.guidance.nice.org.uk/CG27 (date last accessed 25 November 2007).

11. Saithna A, Pynsent PB, Grimer RJ. Retrospective analysis of the impact of symptoms duration on prognosis in soft tissue sarcoma. Int Orthop 2008;32:381-4.

12. Johnson CJ, Pynsent PB, Grimer RJ. Clinical feature of soft tissue sarcomas. Ann $R$ Coll Surg Eng/2001;83:203-5.

13. Widhe B, Widhe T. Initial symptoms and clinical features in osteosarcoma and Ewing sarcoma. J Bone Joint Surg [Am] 2000;82-A:667-74.

14. Okcu MF, Despa $\mathbf{S}$, Choroszy $\mathbf{M}$, et al. Synovial sarcoma in children and adolescents: thirty three years of experience with multimodal therapy. Med Pediatr Oncol 2001;37:90-6.

15. Okcu MF, Munsell M, Treuner J, et al. Synovial sarcoma of childhood and adolescence: a multicenter, multivariate analysis of outcome. J Clin Oncol2003;21:1602-11.

16. Brecht IB, Ferrari A, Int-Veen C, et al. Grossly-resected synovial sarcoma treated by the German and Italian Pediatric Soft Tissue Sarcoma Cooperative Groups: discussion on the role of adjuvant therapies. Pediatr Blood Cancer 2006;46:11-17.

17. Israels SJ, Chan HS, Daneman A, Weitzman SS. Synovial sarcoma in childhood. AJR Am J Roentgenol 1984;142:803-6.

18. Damron TA, Beauchamp CP, Rougraff BT, Ward WG Sr. Soft-tissue lumps and bumps. Instr Course Lect 2004;53:625-37.

19. Grimer RJ, Sneath RS. Diagnosing malignant bone tumours. J Bone Joint Surg $[\mathrm{Br}]$ 1995;72-B:754-6.

20. Ichinose H, Wickstrom JK, Hoerner HE, Derbes VL. The early clinical presentation of synovial sarcoma. Clin Orthop 1979;142:185-9.

21. Jones BC, Sundaram M, Kransdorf MJ. Synovial sarcoma: MR imaging findings in 34 patients. AJR Am J Roentgenol 1993;161:827-30.

22. Campanacci M, Enneking WF. Synovial sarcoma. In: Campanacci M, Enneking WF, eds. Bone and soft tissue tumors. Second ed. New York: Springer-Verlag, 1999:110926.

23. Springfield DS, Gebhardt MC. Bone and soft tissue tumors. In: Morrissy RT, Weinstein SL, eds. Lovell and Winter's pediatric orthopaedics. Fifth ed. Vol. 1. Philadelphia: Lippincott Williams \& Wilkins, 2001:544-62.

24. Richardson ML, Kilcoyne RF, Gillespy T 3rd, Helms CA, Genant HK. Magnetic resonance imaging of musculoskeletal neoplasms. Radiol Clin North Am 1986;24:25967.

25. Ayoub KS, Davies AM, Mangham DC, Grimer RJ, Twiston Davies CW. Synovial sarcoma arising in association with a popliteal cyst. Skeletal Radiol 2000;29:713-16.

26. Virkus WW. Evaluation of masses around the knee. Knee Surg 2005;18:292-7. 